História (São Paulo)

Evita Perón y el Che Guevara. De la historia a la construcción literaria del mito biográfico

Evita Perón e Che Guevara. Da história à construção literaria do mito biográfico

Evita Perón and “Che” Guevara. From history to literary construction of biographical myths

Resumen: Eva Perón y el Che Guevara son dos de las figuras paradigmáticas argentinas, conocidas internacionalmente a través no sólo de sus vidas, que pueden reconstruirse a partir de documentos históricos, sino por el mito nacional - e internacional - que la muerte temprana ha configurado con ambos mediante la ayuda de la literatura y el cine, expandiendo ficcionalmente el matiz revolucionario de su accionar. El presente texto se propone, en consecuencia, dar cuenta de esas "capas" ficcionales que conforman la construcción estética de los dos mitos biográficos e inciden en la evaluación de sus protagonistas reales, modelando la percepción de ambos, particularmente, la considerada por el gran público más que por los especialistas.

Palabras clave: Eva Perón; Ernesto Guevara; mito biográfico.

Resumo: Eva Perón e Che Guevara são duas das figuras paradigmáticas argentinas, conhecidas internacionalmente não apenas em razão de suas vidas, que podem ser reconstruidas a partir de documentos históricos, mas pelo mito nacional - e internacional - que a morte precoce de ambos configurou mediante a ajuda da literatura e do cinema, expandindo-se em termos ficcionais a marca revolucionária de suas ações. O presente texto se propõe dar conta das "camadas" ficcionais que conformam a construção estética desses dois mitos biográficos e incidem na avaliação de seus protagonistas reais, de modo a modelar a percepção de ambos, em particular pelo grande público.

Palavras-chave: Eva Perón; Ernesto Guevara; mito biográfico.

Abstract: Eva Peron and Che Guevara are two of the Argentine paradigmatic figures, internationally known through not only their lives, which can be reconstructed from historical documents, but by the national - and international - myth that early death has built for both, with the help of literature and film, fictionally expanding the revolutionary nuances in their actions. This text is proposed, therefore, to present these fictional "layers" that make up the esthetic construction of the two biographical myths having impact on the perception of both true characters, particularly the considered by great public.

Keywords: Eva Perón; Ernesto Guevara; biographical myth. 


\title{
Evita Perón y el Che Guevara. De la historia a la construcción literaria del mito biográfico
}

Las biografías de Eva Perón y Ernesto Guevara se presentan, en sus configuraciones narrativoliterarias, como un lugar paradigmático de encuentro entre subjetividades diversas de escritores que tejen con ellas un entramado que va desde la historia al mito, desde lo documentado a su ficcionalización: trama de realidad, leyenda urbana e imaginación literaria donde se concentra la ideología como idealización o denostación, y con ella, una metonimia de aquello que denominamos "identidad nacional”; a través de éstas utilizadas como plataformas de la imaginación, los diferentes autores revalorizan tanto el pasado como las relaciones sociales implicadas en él, construyen puentes entre memoria y olvido, y dan cuenta, inscribiéndola en la contemporaneidad de sus textos, de la conflictiva historicidad en medio de la cual ellos mismos se insertan como actores sociales.

\section{El polen de la biografía de Eva cae sobre el relato}

\author{
Evita vive \\ Graffitti peronista de los '70 \\ ¡Viva el cáncer! \\ Graffitti antiperonista del '52
}

Entramos juntos a la cámara mortuoria. Sobre su lecho dormía para siempre el espectro de una rara, tranquila belleza, liberada, al fin, del cruel tormento de una materia hasta el límite corroída y de la tortura mental sostenida por la ciencia que, esperando el milagro, prolonga el suplicio.

Pedro Ara, El caso Eva Perón

Poco a poco, Evita fue convirtiéndose en un relato que, antes de terminar, encendía otro. Dejó de ser lo que dijo y lo que hizo para ser lo que dicen que dijo y lo que dicen que hizo. [...]

Tomás E. Martínez, Santa Evita

Cuando los buitres te dejen tranquila y huyas de las estampas y el ultraje empezaremos a saber quien fuiste. [...] Cuando hagamos escándalo y justicia el tiempo habrá pasado en limpio tu prepotencia y tu martirio, hermana.

María Elena Walsh, "Eva", Cancionero contra el mal de ojo

Ella se fue / solo quedé/ patria en remate /llorando.... Patria en mierda, colonia/ mujer, / mujer querida.

Leónidas Lamborghini. "Payada", en Partitas. 
Acatando el orden en que se sucedieron históricamente, comenzaremos con el tratamiento narrativo de Evita. Su historia "oficial” se urde a partir de una muerte que resignifica su breve e intensa vida política, creando el mito póstumo: a partir del embalsamamiento, que dota a su cuerpo de dimensión espectacular, se le impide la naturalidad de la muerte igualadora, se la convierte en conflictivo cadáver legendario por incorruptible, en memoria histórica itinerante, rebelde, materializada en esa sublevada momia que no acepta su destino tan incierto como el del peronismo sin ella. La literatura retoma y ficcionaliza esta macabra historia en versiones que van desde el asombro a la rabia, desde el odio a la paródica santificación.

Aún a Alfonso Crespo - historiador y diplomático boliviano, director del diario La Razón de La Paz- le resultó difícil apartarse de la tentación ficcionalizadora cuando escribía su biografía de Eva; su epígrafe irradia la sugestión encantadora de la historia fantaseada:

Había una vez, en un país remoto, una actriz joven y bella, que se ganaba afanosamente la vida. Cierto día, el rey la vio en un estadio y, cautivado por ella, la hizo su esposa. Cuando el rey estuvo en peligro, ella convocó al pueblo para defenderlo. Fue tan implacable con sus enemigos como generosa con los humildes, entre quienes repartió dádivas y consuelo. Murió muy pronto devorada por el cáncer. Su pueblo no la olvidó jamás. Aquella mujer se llamaba Teodora. Fue emperatriz de Bizancio, hace quince siglos .

La transcripción de una breve biografía de Teodora dada por el diccionario Salvat sostiene la comparación de Crespo:

Emperatriz de Bizancio, esposa del gran emperador Justiniano (508-548). Era actriz e hija de un guardián de osos del hipódromo. Fue primero la amiga y después la esposa del Emperador, y al decir de sus contemporáneos, era de una belleza soberana. Desde el descubrimiento de la Historia secreta de Procopio, en el siglo XVI, Teodora ha sido presentada como una vulgar cortesana, desfigurando a la gran emperatriz que realmente fue. Colaboró en un modo constante en la obra de gobierno de su esposo, de tal manera, que en muchas empresas de Justiniano se descubre el talento y la sagacidad política de Teodora. Cuando la famosa sedición de Nika en 532, dio muestras de gran entereza, oponiéndose a la huída de su esposo, que hubiera ocasionado la pérdida segura de la monarquía. Después de su muerte en 548, Justiniano fue perdiendo cada vez más su energía y abandonando sus tareas de gobierno. Teodora, rodeada de la majestad y pompa de su corte Bizantina, aparece en uno de los dos bellos mosaicos del siglo VI que decoran el presbiterio de la Basílica de San Vital de Ravena.

Estas citas nos marcan un rumbo de trabajo, ya que es nuestro propósito hacer hincapié en los hechos y discursos sobre Eva como cuerpo político y como corpus literario, ese cuerpo donde - como ha dicho Sarlo acerca del peronismo - "por primera vez en la historia coincide de modo sorprendente 


\title{
Evita Perón y el Che Guevara. De la historia a la construcción literaria del mito biográfico
}

para todos, una identidad política con identidades culturales y sociales". (SARLO, 2001, p. 38). La cita de Sarlo, breve y utilísima para contextualizar el peronismo, continúa así:

\begin{abstract}
Por primera vez se incorporan a la esfera pública nacional los habitantes de las provincias más lejanas. En este sentido, y no sólo en un sentido ideológico que habría que discutir en profundidad, el peronismo es nacionalizador. En el curso de diez años, casi nadie queda fuera de una máquina gubernamental extensa y gestionada eficazmente como agencia cultural y política. No se puede exagerar el impacto del peronismo en la sociedad argentina de los últimos cincuenta años. Partió el campo intelectual y cultural con un corte nítido de profundidad inédita y, en muchos casos, irreversible.
\end{abstract}

Eva, que convivía con Perón desde el 1943, hace su aparición histórica durante el movimiento popular de octubre del 45, que reclama la libertad del entonces Coronel encarcelado y consigue su libertad; su vida política duró desde esa presencia pública hasta su muerte (su "paso a la inmortalidad", como se decía oficialmente en los medios masivos), en 1952, de un cáncer uterino que dejó avanzar irresponsablemente, (quizás agravado por una anorexia que ningún biógrafo menciona como tal, pero que varios insinúan sin rotularla) y aun abofeteando a Ivanissevitch - el médico y ministro de educación que le señalara la necesidad de reposo y tratamiento - absorbida por el trabajo para sus “descamisados" en la Fundación que ella misma creara.

Esos casi siete años de controvertida vida pública son los que sostuvieron la "vitalidad" de su cadáver embalsamado, determinando macabras realidades (el secuestro y la profanación) y leyendas urbanas tejidas sobre su cuerpo desde la ignorancia (versiones sobre la multiplicación en muñecas, o el vaciamiento de sus entrañas). Sarlo ha señalado también: "un solo cadáver argentino nos ha proporcionado, en los últimos tiempos, una verdadera acumulación de planos documentales y ficcionales, como si no hubiera forma de pensar la profanación del cuerpo de Eva Perón fuera del marco del sensacionalismo". (SARLO, 2000, p. 152). Luego, se trató de soslayar su historia por temor a la herencia proveniente de esa breve e intensa vida política y se condenó su cuerpo a la usura de la propia historia.

Entre discursos y realidades, la momia crece paradójicamente viva en el mito tutankamónico que saquea su biografía, redefiniéndola; esa posibilidad reordenadora y corrosiva determinada por la insepultura o la expatriación, traza una diferencia entre cuerpo muerto y cadáver: en el primero termina la historia, mientras, el cadáver sigue reorganizándola, robándole partes que legendariza, magnificando el pasado e inquietando el presente. La historia de Eva se convierte en una tanatografía, en la oximorónica biografía de un cadáver iniciada con su funeral "homérico". A partir de entonces, se la obliga a la leyenda de su cuerpo incorruptible, sacralizada reliquia política laica, que es memoria História (São Paulo) v.33, n.1, p. 109-123, jan./jun. 2014 ISSN 1980-4369 
histórica itinerante, rebelde, presentificada en la sublevada momia que no acepta su destino tan incierto como el del peronismo sin ella; Eduardo Galeano, en Memorias del Fuego, da una versión lírica y sucinta de su muerte y del funeral: "ante el cuerpo de Evita, rodeado de claveles blancos, desfila el pueblo llorando. Día tras día, noche tras noche, la hilera de antorchas: una caravana de dos semanas de largo [...] Muerta Evita, el Presidente Perón es un cuchillo sin filo”. (GALEANO, 1986, p. 175). Se transforma así en el cuerpo indestructible que mitifica los logros y equívocos de su existencia histórica.

Estas historias perviven en la literatura, donde Eva se extiende desde el rechazo a su figura hasta la migración de su cadáver y la santidad paródica: la ficción trabajará a partir de ello en innumerables versiones que la tienen por centro, de las cuales queremos resaltar aquí aquellas que mejor representan los conflictos ideológicos que cada autor confronta en su cuerpo vivo o muerto; leídas como serie, dan cuenta de una periodización histórica que muestra diferentes conflictos epocales de interpretación.

Julio Cortázar aludió a ella en una novela escrita antes de su muerte en 1952, aunque permaneció inédita hasta 1986; texto caótico, grotesco, en el que un grupo de amigos recorre un Buenos Aires insólito, donde se cumplen rituales extraños, algunos multitudinarios -acudir a la Plaza de Mayo a adorar un hueso- a los que se vuelca en peregrinación la gente llegada en trenes desde las provincias. En medio de un círculo, se adora a una mujer vestida de blanco. De esa novela, dice Tomás Eloy Martínez en la suya:

El terror que flota en el aire no es el terror a Perón sino a Ella, que desde el fondo inmortal de la historia arrastra los peores residuos de la barbarie. Evita es el regreso de la horda, es el instinto antropófago de la especie, es la bestia iletrada que irrumpe, ciega, en la cristalería de la belleza. (CORTÁZAR, 1995, p. 197).

Borges y Onetti comienzan una serie literaria producida por escritores que trabajan sobre su cadáver; la visión de estos autores, quienes "a pesar de las diferencias ideológicas que los separan, resultan emparentados por la servidumbre semiológica a un cuerpo muerto de Evita pensado como cierre y clausura". (AVELLANEDA, 2002, p. 124). Ambos dan comienzo "a una tradición textual sobre los restos, sobre lo que resta dentro de la muerte de Eva: una Eva pensada en la muerte, cerrada por dentro del marco de su muerte" (AVELLANEDA, 2002, p. 124): el escritor uruguayo, en 1953, en el cuento "Ella", conocido tardíamente en la edición de sus obras completas impressa en los 90, con el cinismo misógino de los machos tangueros propio de esa época, capta con crueldad el ritual agónico y con realismo el funeral; usa el tema para mostrar la división de clases sociales delimitadas entre la resentida liberación de los ricos y la adoración de los pobres, conmovidos ante su retornada orfandad. 


\section{Evita Perón y el Che Guevara. De la historia a la construcción literaria del mito biográfico}

Borges titula "El simulacro" a su breve cuento publicado en El Hacedor (1960), sobre la manipulación y el uso político del velatorio y del cuerpo; en éste Eva es presentada como una muñeca rubia y Perón como una suerte de payaso con conciencia de qué espectáculo necesita "el crédulo amor de los arrabales" para configurar "una crasa mitología"; usa el motivo para negar el liderazgo populista masivo que siempre ha rechazado, dominándolo convertido en simulacro, conjurándolo en el símbolo de la política vista como ficción.

La visión de ambos resulta opuesta a la de los revulsivos autores gay producidas en los setenta (época de resignificación política del peronismo en la Argentina). Éstos (COPI, PERLONGHER), autoinstalados fuera de la ideología patriarcal, representan a Eva junto a ellos, irreverente, en el margen, la homologan a sí con el loco desenfreno de una diosa pagana "sacrílega". Hay, en los autores mencionados, un empecinamiento por construir a Eva como mito amenazador de una estereotipada identidad masculina: Copi, en su obra teatral sobre Eva-escrita originalmente en francés, ya que su económicamente poderosa familia se había exiliado en Francia durante el peronismo, cuando él era un adolescente- pretendía que el personaje fuera representado por un travesti - ya que, según señalaba, Eva era "una mujer de pelo en pecho"-; este empecinamiento le valió el incendio producido por la larga mano de la militancia peronista, del teatro donde se estrenaría la obra en París; Néstor Perlongher la representa como una "dealer" que, volviendo de la muerte, reparte droga en una orgía gay o le hace una fellatio a un negro. Para ambos existe una "Evita erotizada que, postulada como viva más allá de la muerte, puede garantizar la existencia de un paraíso en la tierra”. (AVELLANEDA, 2002, p. 121).

"Esa mujer" de Rodolfo Walsh -relato ligado a la novela Santa Evita (ya que puede leerse como su continuación: trazado ficcional de las respuestas faltantes a las preguntas periodísticomilitantes planteadas allí)- de principios de los sesenta, es el primer texto literario -o más claramente, ya que se basa en una entrevista real, del naciente género de non-fiction inaugurado por Walsh en Latinoamérica antes de la publicación de A sangre fría en USA- que manifiesta, en clave policial, la preocupación militante por desentrañar el misterio del lugar donde yace el cadáver y la obstinada resistencia militar a proporcionar información: diálogo tentativo en busca de datos que no se revelan, cuyos personajes no ficticios son un periodista (Walsh) y un coronel que ha tenido a su cargo la "protección" (Moori Koening) .

En él, Eva es un ausente cuerpo-metáfora de la nación - al menos, de la parte peronista de la nación - arrebatada y profanada por el paranoico militarismo "gorila", golpista. Cabe señalar acá que el término "gorila" es ampliamente utilizado en Argentina para designar al antiperonismo y a los antiperonistas de la década del 50. Su origen data de una canción popular de la década que fue 
resemantizada por la radio de aquellos días. En ese momento -y en el sentido que lo utilizamos refiriéndonos al Coronel del cuento - designaba en particular al oligarca reaccionario católico o al militar liberal (ala de las Fuerzas Armadas opuesta al populismo nacionalista de Perón, que será la que lo derrocará posteriormente). El investigador John Kraniauskas dice al respecto: "Leído como texto histórico-cultural ¿de qué trata 'Esa mujer', qué tematiza? Precisamente el hecho de que Eva Perón, como fetiche político, ¡era una de las 'fuentes de producción simbólica' más importantes del peronismo!. Es decir, un elemento fundamental del 'peronismo imaginario' - y fascinante". (KRANIAUSKAS, 1994, p. 108).

Walsh termina su propio relato diciendo "la voz del coronel me alcanza como una revelación: — Es mía - dice simplemente -. Esa mujer es mía" (WALSH, 1961, p. 19); en ese final, no sólo se aprecia la "vitalidad" del cadáver (que es una mujer y no un cuerpo muerto) sino que mujer y "patria" se homologan bajo la posesión militar; el cuerpo de Evita (aunque no se la mencione sino sólo como “esa mujer”) es allí central: metaforiza, como se ha señalado, la propia nación expropiada por el militarismo golpista.

La novela Santa Evita, de Tomás Eloy Martínez, como biografía retrospectiva de Eva y progresiva de su cadáver, es la epopeya oximorónica de una heroína "postfuneraria”, construcción de la historia donde ya no era previsible la historia; como anuncia la contratapa "el personaje central de esta novela es un cuerpo [...] que [...] cobra una dimensión inesperada y redefine en forma mítica a la mujer que fue en vida”. El cuerpo personaje, a caballo entre el melodrama, la historia, y el mito canonizador desde el "sol líquido" de sus entrañas detenidas, incólumes ante la muerte, persistirá en la memoria de los lectores más allá de la biografía y más vivo que su realidad de muerte sin descomposición.

Si en el relato de Walsh Eva es ausencia, en la novela de Martínez es la presencia macabra, abrumadora, obstinada; para hurgar en el sensacionalismo, debe apuntar a la presencia, a la perenne y obscena presencia del cuerpo-mito. Su autor crea a Eva cadáver exquisito como cuerpo muerto irradiante en cada interpretación expresada sobre ella, y como texto de voces múltiples donde, como en el mito, la autoría se desvanece en función de las versiones del héroe. Allí, ese perturbador cadáver insurrecto al que es imposible convertir en detritus, se torna símbolo de la resistencia peronista, de la división nacional silenciada y encubierta, de todo cuanto pretendía dejarse fuera de la historia oficial: metáfora de la presencia insoslayable del pasado en el presente que hace también de la identidad nacional un cadáver exquisito. 


\section{Evita Perón y el Che Guevara. De la historia a la construcción literaria del mito biográfico}

Si a la muerte de Eva el Papa recibió innumerables pedidos para considerar su canonización, Tomás Eloy Martínez, desde el título, se la otorga en su novela, en el engrandecimiento ficcional de su vida contada, como en las hagiografías, desde la dignidad póstuma de la canonización que, a su vez, se deconstruye aquí en parodia, apta para una santa pagana, arrabalera; juega así con la ambivalencia estético-religiosa que, de lo canónico, se deposita en la santidad ficcional.

Abel Posse, en La pasión según Eva, señala también desde el título un intento divinizador, pero por ser acólito, la seducción del "milagro" lo enceguece, inhibiendo el logro. No es Eva quien narra su "Pasión", sino múltiples voces en sospechosa sintonía reverencial, intentando una recuperación "coral" de la memoria, en función de la llegada de la muerte (lugar fundante del relato), pero una hagiografía que desatiende el pecado para exaltar, genuflexa, el sacrificio, vuelve inverosímil los portentos y tendenciosamente pedagógica la conmemoración. La novela se vuelve propagandístico artificio persuasivo.

Una cita de Jean Franco acerca de la similitud entre las tramas de ciertas novelas semanales y las historias religiosas, lleva a pensar en la diferencia entre la novela de Posse y la de Martínez justamente por lo que dice acerca de los personajes de las hagiografías:

[En la historia religiosa] las diversas persecuciones y eventos de la vida de una persona santa tienen un sentido trascendental una vez que se ven desde la perspectiva de Dios. Sin embargo, cuando este tipo de expresión se despliega en una sociedad secular, provoca un problema narrativo. La trama cuenta sólo parte de la historia, puesto que no hay un sistema de creencia universal sobre el que pueda descansar. De esta manera el sentido de los acontecimientos no queda claro, a menos que nos sea interpretado por la voz extra-narrativa, cuya autoridad es deliberadamente vaga. (FRANCO, 1996, p. 66).

Precisamente, Posse quiere ocupar el lugar del "ojo de Dios" -por ello el narrador principal, a cuya palabra se vuelve constantemente, es el padre Benítez, confesor de Eva- entonces, la perspectiva divina, aplicada al laicisismo de la política, termina pareciéndose demasiado al panfleto. Martinez, en cambio, no pretende "trascendentalizar", sólo canoniza paródicamente, porque sabe que no hay avales universales y que, por muchas que sean las versiones, son sólo partes de una totalidad inabarcable cuya complejidad es tan inaccesible como la de la lógica divina.

Finalmente, y cerrando - al menos hasta la actualidad - la serie aludida, el relato de estética postmoderna de Rodrigo Fresán, ya en los noventa, titulado "El único privilegiado", convierte a Evita en un luminoso y distante objeto pop, metáfora de la percepción de una generación joven y posterior acerca de ella, que ha olvidado la historia y sólo concibe a ésta como relato seductor y mentiroso. 


\section{La ficción sobrevuela al "Che" Guevara}

Es innegable que de todas las figuras revolucionarias de los últimos tiempos, la de Ernesto "Che" Guevara ha sido una de las que más se ha expandido, incluso mitificándose en un nivel que trasciende tanto las fronteras de Argentina y Cuba como, asimismo, las latinoamericanas, volviendo a su dueño un ícono-paladín internacional de las causas justas. Es curioso que ese mito, fundado en una historia tanto personal como social sin claudicaciones, no se haya extendido ni haya sido avalado en la Argentina como lo ha hecho en el resto del mundo, aun cuando se inicia en el propio país y comparte características con otros mitos locales -con Eva Perón la preocupación por los desclasados, por los parias de la historia, aunque desde una práctica y una interpretación absolutamente diversa - y también con ella, como asimismo con Carlos Gardel, la muerte en edad temprana, que tan salvífica es ante la crítica histórica y tan oportuna para apuntalar la veneración mítica.

En cambio de lo dicho sobre la imagen biográfico ficcional de Eva, la del Che Guevara no comparte esa asiduidad del retorno literario. Por ello, a los argentinos suele sorprendernos esa búsqueda internacional del Che que deja sus huellas en algún film de Federico Fellini - Prova d'Orchestra (1979) -, como asimismo en los más próximos hitos norteamericanos: tanto Evita narrada por el Che en el film de Alan Parker (1996), como el boom que produjo en su momento, en ese mundo académico, el texto de Patrick Symmes: Chasing Che: a motorcycle journey in search of the Guevara Legend, (2000), que apunta a la búsqueda de un Che prístino, aún al margen de la guerrilla y del marxismo, en el momento fundante de la constitución de su realidad histórica y su leyenda política - el mismo Che que luego mostrará al mundo el brasileño Walter Salles en su film Diarios de motocicleta.

Respecto de las películas mencionadas, puede decirse que en la de Fellini, si bien la imagen no se explotaba allí ni en su valor biográfico ni en el histórico, viéndola es fácil percibir cuáles eran las condiciones tanto del Che como de las guerrillas latinoamericanas que la izquierda europea comenzaba a mitificar y a veces a mezclar en un caos de ideologías que en Latinoamérica divergían principalmente entre modos de acción rurales y urbanos, ya fuera que siguieran el modelo de los diarios del Che, o el de Los condenados de la tierra, de Franz Fanon. El film se mostraba, a través del ensayo de una orquesta que jamás lograba ponerse de acuerdo - no por falta de talento, sino de solidaridad y espíritu cooperativo, acompañada a su vez por excesos de virtuosismo individualista -, como una metáfora aguda de la ingobernabilidad de la joven izquierda italiana (o europea) - quizás en una alusión directa a las Brigadas Rojas que sembraban el terror en la Italia de esos tiempos - y del caos de gobernabilidad 


\section{Evita Perón y el Che Guevara. De la historia a la construcción literaria del mito biográfico}

que esto producía, pero sin caer en ningún momento en la crítica reaccionaria, sino desde una sátira madura que no ocultaba que, para estos jóvenes post setentistas, el Che se volvía un objeto estético a quien se imitaba en la indumentaria descuidada más que en la ideología. La sutileza de la crítica radica precisamente en que ésta no se monta sobre el lenguaje, sino sobre la gestualidad, la escenografía y la música -de Nino Rota- prescindiendo casi completamente del diálogo.

Con referencia al de Alan Parker, cuesta reconocer al Che en el personaje que interpreta Antonio Banderas, pero no es difícil identificar el camino por el cual se intenta integrar la historia: la ciudadanía y la preocupación social diversamente interpretada hace que esa comunión de personajes, que para un argentino (y más aún si es peronista) resulta chocante y arbitraria, se vuelva plausible ante ojos internacionales y así, Guevara-Banderas es el admonitorio crítico del progresivamente fascistizado accionar de Evita-Madonna. Justamente porque no se le puede pedir al arte verdad sino verosimilitud, es que la convergencia de personajes - ácidamente criticada por los sectores más reaccionarios del peronismo nacional como lo fue el mismo film - resulta lúcida, y el planteo de Parker puede rescatar así con inteligencia los puntos extremos de un ideario que, centrado en la preocupación social, en Argentina va desde el populismo conservador de derecha a la pseudo izquierda populista y desde el melodrama a la tragedia. Sólo a modo de leyenda biográfica podían integrarse críticamente esos dos personajes inconciliables en la historia ideológica nacional; en esa legendarización el inverosímil Che artístico se potencia, atemporal, construido sobre una moderación marginal a la guerrilla, pero respetando su intolerancia ante la injusticia; a partir de ello se exploran las aristas de la contradicción ideológica nacional argentina como para explicarlas, de manera accesible y totalizadora, a un público foráneo, ya que - en la visión de Parker - Argentina lo ha parido como al otro extremo de la ideología revolucionaria.

El Che es más bien una figura desvaída en la Argentina, vaciada de peso político más allá de las playeras para turistas, o de algún nostálgico poster descolorido en los centros estudiantiles izquierdistas en las Universidades estatales, una figura a la que la política no ha regresado luego de la traumática derrota de las mesiánicas organizaciones guerrilleras locales y del peso aplastante de la dictadura.

Fue Julio Cortázar quien, con la mediación ficcionalizadora de su literatura prohibida por el militarismo golpista de los 70s, pero leída clandestinamente, puso frente al honesto heroísmo de Guevara a la generación de quienes estábamos entre la adolescencia y los veinte años durante la dictadura y éramos niños cuando lo asesinaron: el cuento "Reunión" - una de las principales razones para que los militares proscribieran la lectura del autor - publicado en Todos los Fuegos el Fuego (1971), presenta un entrañable Che que se construye sobre dos fuentes: Pasajes de la Guerra 
Revolucionaria, del propio Che, a quien cita en el epígrafe, y el prólogo de Fidel Castro al Diario del Che en Bolivia, para lo referido a esa personalidad, que dibuja entre la lucidez, el humor, la preocupación, el idealismo y la entrega. Desde el epígrafe, construye a su personaje a través de aquello que lo hermana con él mismo: el humanismo de la tradición literaria y el de la música de Mozart; el Che se reconoce a través del relato - desarrollado en primera persona testimonial - por el acento porteño, por la sensibilidad humorística de las observaciones, por la preocupación hacia el prójimo y por el agónico ahogo del asma que modula su voz.

El momento que se retrata en la narración es el de los días que siguen al desembarco, en la tortuosa caminata hacia la Sierra, jornadas de tensas dudas ante la incertidumbre del logro, sin saber siquiera qué compañeros permanecen vivos, pero con la certeza de que las bajas son numerosas. Los estragos de la lucha son presentados sin patetismo, con la sobria responsabilidad solidaria que caracteriza también los verdaderos escritos del Che, y sin escatimar la crítica social. Así, gradualmente, avanzando en comentarios que despliegan su personalidad firme y sencilla y su voluntad sin claudicaciones, comienzan el ascenso de la Sierra hacia la reunión final, que garantizará el triunfo; si bien el cuento termina aún en la duda, Cortázar aprovecha una de las anécdotas que el Che relata para darle a la narración la expectativa del triunfo, aunque también está presente la intuición de la propia muerte del personaje.

Si toda una generación de jóvenes leyó al Che de Cortázar, no sucedió lo mismo con el que escribe poéticamente el recientemente desaparecido poeta Juan Gelman, dos años antes que él, a pedido de Casa de las Américas, para una publicación de homenaje literario tras su asesinato. En su poema, titulado "Pensamientos", Guevara ya está muerto; su figura surge allí del canto de un anarquista detenido, precisamente, porque de su guitarra salió el Che:

Soy de un país donde hace poco Carlos Molina/uruguayo anarquista y payador/fue detenido/en Bahía Blanca al sur del sur/frente al inmenso mar como se dice/fue detenido por la policía/Carlos Molina estaba/ cantando hilando coplas/sobre el océano enorme los viajes/los monstruos del océano enorme [...]/cantaba como siempre bellezas y dolores cuando/de pronto el Che empezó a vivir a morir en su guitarra/y así la policía lo detuvo.

Su biografía es utilizada, a partir de allí, para hablar de las contradicciones de la nación que lo abandonó:

soy de un país donde se llora por el Che o en todo caso/se canta por el Che y/algunos están contentos con su muerte/"vieron" dicen "estaba equivocado la cosa no es así"/dicen y cómo carajo será la cosa no lo dicen o/prefieren recitar viejos versículos 
o/indicar señalar aconsejar mientras/los demás callan/miran al aire con los ojos perdidos/el comandante Guevara entró a la muerte/y allá andará según se dice/soy de un país donde costó creer que se moría y muchos/un servidor entre otros/se consolaba así:/"pero si él dice no hay que/pelear hasta morir hay que/ pelear hasta vencer entonces no está muerto"/ otros lloraban demasiado como quien/ha perdido a su padre y yo creo/que él no es nuestro padre y/con todo respeto creo que/está mal llorarlo así/ soy de un país donde los enemigos no/pudieron depositar un solo insulto una sola/ suciedad una sola pequeña porquería/sobre él y hasta algunos/lamentaron su muerte no/por bondad o humanidad o piedad/ sino porque esos viejos perros/o muertos con permiso sintieron por fin un enemigo que/valía la pena/que un rayo de peligro/entraba en escena y entonces/iban a poder morir en serio/a manos o a balas de verdad [...]

O para formular una crítica certera contra el partido comunista argentino:

ahora nomás/el comandante Guevara entró a la muerte/y allá andará según se dice/pregunto yo/¿quién habrá de aguantarle la mirada?/¿ustedes momias del partido comunista argentino?/ ustedes lo dejaron caer/¿ustedes izquierdistas que sí que no?/ustedes lo dejaron caer/¿ustedes dueños de la verdad revelada?/ustedes lo dejaron caer/¿ustedes que miraron a China sin entender que/mirar a China en realidad/era mirar nuestro país?/ustedes lo dejaron caer/¿ustedes pequeñitos/teóricos del fuego por correo partidarios/de la violencia por teléfono o/del movimiento de masas metafísico?/ustedes lo dejaron caer/¿ustedes sacerdotes del foquismo y más nada?/ustedes lo dejaron caer/iustedes miembros del club/de grandes culos sentados en "lo real"?/ustedes lo dejaron caer/¿ustedes los que escupen/sobre la vida sin/advertir que en realidad están/ escupiendo contra el gran viento de la historia?/ustedes lo dejaron caer/soy de un país donde al comandante Guevara/lo dejaron caer:/los militares los curas los homeópatas/los martilleros públicos/los refugiados españoles masoquistas judíos/los patrones y/los obreros también por ahora.

O para la propia autocrítica: "soy de un país donde yo mismo lo dejé caer/y quién pagará esa cuenta quién". Y luego de apelar al lector a seguir leyendo la línea de sangre que escribían los periódicos sobre Vietnam o sobre Bolivia, concluye con las preguntas sin respuestas para una militancia que comenzaba a ahogarse anunciando el futuro trágico que envolvería a la izquierda tras su muerte, preguntas que todavía están sin respuesta y que, posiblemente, estén ya clausuradas por la historia:

el poeta/apenas sabe vigilar/Che Guevara/ahora deseo un gran silencio/que baje sobre mi corazón y lo abrigue/padre Guevara ¿qué será de tus hijos?/¿por qué te fuiste hermoso/sobre caballos de cantar?/¿quién habrá de juntarte otra vez?

Entre otras manifestaciones - como la biografía del Che de Paco Ignacio Taibo o la de Pacho O’Donnel (no ficcionales) - es interesante resaltar la visión que Ricardo Piglia, siguiendo su tradición de instalarse productivamente entre la literatura, la historia y el ensayo, escribe, en El último lector, 
trabajando sobre la imagen del Che como lector: "Ernesto Guevara, rastros de lectura". Aunque nunca deslumbrado con Cortázar, cita allí el cuento sobre el Che para graficar su pasión por la lectura y cómo ésta "modela y transmite la experiencia en soledad" (PIGLIA, 2005, p. 105) donde

No se trataría sólo del quijotismo en el sentido clásico, el idealista que enfrenta lo real, sino del quijotismo como un modo de ligar la lectura y la vida. La vida se completa con un sentido que se toma de lo que se ha leído en la ficción (PIGLIA, 2005, p.104),

lo que se ha leído aún trepado a los árboles en el fragor de la guerrilla y la proximidad de la muerte en Bolivia (PIGLIA, 2005, p. 106), experimentando la paradoja de su "persistencia y fragilidad" casi viciosa (PIGLIA, 2005, p. 107) porque lo aproxima a la evasión.

De un rasgo -el contraste entre la figura sedentaria del lector con la del guerrillero en marcha que no abandona sus libros haciendo más lenta y fatigosa la marcha-, deriva un ejemplo "antagónico y simétrico": el de Gramsci, leyendo quieto en la cárcel fascista cuanto cayera en sus manos; a través de ello Piglia logrará oponer brillantemente los dos modelos políticos: la teoría del foco y la de la hegemonía.

Un aspecto que señala Piglia, referente a estos modelos izquierdistas de pensamiento, remite a la idea de vida y de utilidad de la biografía para el propio Che; dice:

En verdad, para Guevara, antes que la construcción de un sujeto Revolucionario, de un sujeto colectivo en el sentido que esto tiene para Gramsci, se trata de construir una nueva subjetividad, un sujeto nuevo en sentido literal, y de ponerse él mismo como ejemplo de esa construcción. (Piglia, 2005, p. 109-110).

Para autores de ficción ya más distantes de las utopías setentistas revolucionarias que idealizaban al Che, como son Jesús Díaz en Las iniciales de la tierra (1992), o Eliseo Alberto en Caracol Beach (1998) - novelas en las que éste aparece como personaje secundario (el militante absurdo de la primera) o como trasfondo innombrado (el soldado cubano que enloqueció en la guerrilla congolesa en la segunda) - esa idea suya de construir una nueva subjetividad, un sujeto nuevo para quien su conducta de superhombre sirviera de modelo, se estrella en la parodia vaciada de sentido, o en la locura desatada que arrastra en su torbellino a los demás -inocentes- en su desborde, con consecuencias trágicas: el modelo guevarista comienza, en estas novelas, a mostrar su idealismo mesiánico como costado débil.

Para concluir, puede decirse entonces que, a través de estos usos ficcionales de ambas biografías que hemos reseñado brevemente aquí, tanto la vida y el cuerpo muerto de Evita como la figura del Che, 
se resignifican como memoria imaginada en la que cada autor rescata los aspectos que le interesa resaltar en función de la propia concepción, tensa, de historia e identidad nacional y de lo que quiere transmitir a través de ese constructo conflictivo que edifica en la ficción. La diferencia interpretativa a la que remiten estos personajes históricos en sus biografías fictivas, nos alerta entonces sobre la saturación de ideología que los ha rodeado, entendiendo ese término en su máximo valor de alienación, es decir, cuando ya es imposible percibirla como tal porque lo político, como ha dicho Jameson "implacablemente impulsado por la reificación acumulada, finalmente se ha convertido en un genuino Inconsciente".

\section{Referências}

ALBERTO, Eliseo. Caracol Beach. 1998. Madrid: Santillana, 2001.

ARA, Pedro. El caso Eva Perón. (Apuntes para la historia). Madrid: CVS Ediciones, 1974.

AVELLANEDA, Andrés. Evita, cuerpo y cadáver en la literatura. Evita. Mitos y representaciones. Navarro, Marysa (comp.). Buenos Aires: Fondo de Cultura Económica, 2002, p. 101-141.

BORGES, Jorge Luis. El simulacro. Obras completas. Buenos Aires: Emecé Editores, 1974.

CASTRO, Fidel. Una introducción necesaria. Prólogo de El diario del Che en Bolivia. México: Siglo XXI, 1968.

COPI (Raúl Natalio Roque Damonte). Eva Perón. 1970. Trad. Jorge Monteleone. Buenos Aires: Adriana Hidalgo, 2000.

CORTÁZAR, Julio. El examen. Buenos Aires: Sudamericana-Planeta, 1986.

CORTÁZAR, Julio. Reunión. Todos los fuegos el fuego. Barcelona: EDHASA, 1982.

CRESPO, Alfonso. Evita viva o muerta. Barcelona: Fontalba, 1980.

DÍAZ, Jesús. Las iniciales de la tierra. Caracas: Monte Ávila Latinoamericana, 1992.

FRANCO, Jean. La incorporación social de las mujeres. Una comparación de narrativa popular mexicana y norteamericana. In: Marcar diferencias, cruzar fronteras. Santiago de Chile: Cuarto Propio, 1996, p. 49-77.

FRESÁN, Rodrigo. El único privilegiado. Historia argentina. 1991. Buenos Aires: Tusquets, 1998, p. 51- 60.

GALEANO, Eduardo. Memoria del fuego (III). El siglo del viento. Madrid: Siglo XXI, 1986. 
GUEVARA, Ernesto. Pasajes de la Guerra Revolucionaria. La Habana: Txalaparta, 1977.

GELMAN, Juan. Pensamientos. Disponível em: http://www.lexia.com.ar/gelmanpensamientos.htm. Acesso em: 16 jan 2014.

KRANIAUSKAS, John. Rodolfo Walsh y Eva Perón: 'Esa Mujer'. Nuevo Texto Crítico, n. 12-13, p. 105-119, 1994.

MANGUEL, Alberto. The return of the mummy. Brick 56, p. 68-70, Spring, 1997.

MARTÍNEZ, Tomás Eloy. Santa Evita. Barcelona: Seix Barral, 1995.

ONETTI, Juan C. Ella. Cuentos completos. Madrid: Alfaguara, Grupo Santillana, 1999, p. 459-462.

PERLONGHER, Néstor O. Evita vive y Joyas macabras. Prosa plebeya. Ensayos, 1980-1992. Buenos Aires: Colihue, 1997, p. 191-195, 201-202.

PIGLIA, Ricardo: Ernesto Guevara, rastros de lectura. El último lector. Buenos Aires: Anagrama, 2005, p. 103-138.

POSSE, Abel. El Mito. La nación. Cultura. Buenos Aires: 14 jul. 2002.

POSSE, Abel. La pasión según Eva. Buenos Aires: Emecé, 1994.

SARLO, Beatriz. Tiempo presente. Notas sobre el cambio de una cultura. Buenos Aires: Siglo XXI, 2001.

SYMMES, Patrick: Chasing Che: a motorcycle journey in search of the Guevara Legend. New York: Vintage Books, 2000.

WALSH, Rodolfo. Esa mujer. Los oficios terrestres. 1965. Buenos Aires: De la Flor, 1986, p. 9-19.

Cecilia López Badano es doctora y investigadora del Instituto de Investigaciones Lingüísticas y Literarias - Facultad de Lenguas y Letras, Universidad Autónoma de Querétaro, Campus Aeropuerto, Mexico.

Recebido em 04/04/2014

Aprovado em 09/05/2014 